\title{
Ouderinterventie voor gedragsproblemen bij kinderen
}

\section{Even effectief voor verschillende gezinnen?}

\author{
Patty Leijten · Ankie Menting · Leoniek Wijngaards-de Meij · \\ Maartje Raaijmakers · Walter Matthys · Bram Orobio de Castro
}

\section{Samenvatting}

Ouderinterventies gericht op opvoedingsvaardigheden zijn een van de effectiefste strategieën om gedragsproblemen bij jonge kinderen te voorkomen of te verminderen. Het is belangrijk om te weten welke gezinnen baat hebben bij deze interventies. Er zijn namelijk signalen dat gezinnen met een migratieachtergrond of een laag opleidingsniveau deze interventies minder vaak aangeboden krijgen, op basis van de ongefundeerde aanname dat deze interventies voor hen 'niet passend' zouden zijn. Dit geldt ook voor gezinnen met kinderen die naast gedragsproblemen ook ADHD-symptomen of emotionele problemen hebben. Als we beter weten welke gezinnen baat hebben bij ouderinterventies, kunnen we ervoor zorgen dat zo veel mogelijk gezinnen de juiste hulp krijgen.

In dit onderzoek toetsen we of gezinnen die verschillen wat betreft migratieachtergrond, opleidingsniveau, en ernst en opeenstapeling van problemen evenveel profiteren van een ouderinterventie om gedragsproblemen te verminderen. We hebben hiervoor gebruikgemaakt van gegevens van 786 gezinnen (kinderen 2-10 jaar) uit vier Nederlandse wetenschappelijke studies met controlegroepen

Een Engelstalige versie van dit artikel is gepubliceerd in het tijdschrift Prevention Science.

\section{Dr. P. Leijten $(\bowtie)$}

Research Institute for Child Development and Education, Universiteit van Amsterdam, Nieuwe Achtergracht 127, 1018 WS Amsterdam, Nederland

e-mail: p.leijten@uva.nl

Dr. A. Menting · Prof. dr. B. Orobio de Castro

Afdeling Ontwikkelingspsychologie, Universiteit Utrecht, Utrecht, Nederland

Dr. L. Wijngaards-de Meij

Afdeling Methoden en Statistiek, Universiteit Utrecht, Utrecht, Nederland

Dr. M. Raaijmakers

Pro Persona, Nijmegen, Nederland

Prof. dr. W. Matthys

Kinder- en Jeugdstudies, Universiteit Utrecht, Utrecht, Nederland 
naar de effectiviteit van Incredible Years ('Pittige Jaren'). Van de gezinnen had $29 \%$ een migratieachtergrond en was $31 \%$ laagopgeleid.

De resultaten laten zien dat Incredible Years gedragsproblemen bij kinderen vermindert. De effectiviteit van de interventie verschilde niet voor gezinnen met of zonder een migratieachtergrond, voor verschillende opleidingsniveaus of voor kinderen met meer of minder ADHD-symptomen. Kinderen met meer gedragsproblemen en kinderen met meer bijkomstige emotionele problemen lieten de grootste afname van gedragsproblemen zien. Dezelfde ouderinterventie was dus grotendeels even effectief voor diverse gezinnen.

\section{Trefwoorden}

ouderinterventie $\cdot$ gedragsproblemen $\cdot$ diversiteit

\section{Parenting programme for disruptive child behaviour}

Equally effective for diverse families?

\section{Abstract}

Parenting programmes are an effective strategy for reducing children's behavioural problems. It is important to understand who benefits more from these programmes and who benefits less. There are trends that suggest that families with a migration background or lower levels of education are not referred to evidence-based programmes, based on the untested assumption that these programmes do not meet their needs. The same holds for families of children with co-occurring ADHD symptoms and emotional problems. A better understanding of who benefits from parenting programmes will allow more careful matching between families and programmes.

We used data from 786 families (with children aged 2-10 years) from four trials in the Incredible Years parenting programme in the Netherlands. Of these families, $29 \%$ had a migration background and $31 \%$ had lower educational levels.

Our findings show that Incredible Years reduced disruptive child behaviour. Effects did not differ between families with different migration or educational backgrounds, or between children showing more or fewer ADHD symptoms. Children with more severe disruptive behaviour and children with more emotional problems benefited more in terms of reduced disruptive child behaviour. Thus the parenting programme yielded similar benefits for families with diverse backgrounds.

\section{Keywords}

parenting intervention $\cdot$ behavioural problems $\cdot$ diversity 


\section{Inleiding}

Gedragstherapeutische ouderinterventies gericht op opvoedvaardigheden zijn een effectieve manier om gedragsproblemen zoals agressie en boosheid bij kinderen te verminderen (Weisz en Kazdin 2010). In deze interventies leren ouders hoe ze gewenst gedrag bij kinderen kunnen versterken en ongewenst gedrag kunnen verminderen. Niet alle gezinnen hebben evenveel baat bij deze interventies. Gemiddeld een kwart tot een derde van de gezinnen die een ouderinterventie krijgt, profiteert hier niet van (Scott et al. 2001; Shelleby en Shaw 2014). Er is weinig bekend over wat voor gezinnen dit zijn, en waarom ze niet profiteren $(\mathrm{Ng}$ en Weisz 2016). Het is belangrijk om beter zicht te krijgen op deze gezinnen, zodat hulpverlening kan worden afgestemd op de mogelijk andere behoeften van deze gezinnen en hulpverlening ook bij deze gezinnen tot daadwerkelijke vermindering van problemen leidt (Rutter en Pickles 2016). Hoewel niet of nauwelijks onderzocht, zijn er signalen vanuit de praktijk dat gezinnen met een migratieachtergrond of een laag opleidingsniveau minder vaak gestandaardiseerde interventies krijgen aangeboden, op basis van de aanname dat deze interventies voor hen 'niet passend' zouden zijn. Dit geldt ook voor gezinnen met kinderen die naast gedragsproblemen ook ADHD-symptomen of emotionele problemen hebben. Het is belangrijk om te toetsen in hoeverre deze aannames juist zijn, om ervoor te zorgen dat zo veel mogelijk gezinnen de juiste hulp krijgen.

Individuele studies zijn vaak te klein om een goed onderscheid te kunnen maken tussen typen gezinnen die meer of minder baat hebben bij ouderinterventies (Brown et al. 2013). Het kijken naar subgroepen van gezinnen vereist namelijk veel statistische power, en dus een grote groep gezinnen. In deze studie hebben we daarom de gegevens van vier studies samengevoegd. In deze samengevoegde groep van bijna achthonderd gezinnen gaan we na in hoeverre vijf gezinskenmerken de effectiviteit van ouderinterventies beïnvloeden: migratieachtergrond van de ouders, opleidingsniveau van de ouders, ernst van de gedragsproblemen bij de kinderen, bijkomstige aandachtstekort- en hyperactiviteit/impulsiviteit (ADHD-symptomen), en emotionele problemen bij de kinderen.

\section{Migratieachtergrond}

Van gezinnen met een migratieachtergrond wordt soms gedacht dat ze mogelijk minder baat hebben bij opvoedingsondersteuning. De meeste interventies zijn ontwikkeld in westerse landen, zoals de Verenigde Staten of Australië. We weten dat veel van deze interventies ook effectief zijn in andere landen dan waar ze ontwikkeld zijn (Leijten et al. 2016). Toch is het niet altijd zeker of de inhoud van deze interventies (bijvoorbeeld het geven van complimenten aan kinderen) aansluit bij de doelen, normen en waarden van ouders afkomstig uit migrantengroepen (Miranda et al. 2015), die zowel een andere culturele achtergrond als vaak een lagere sociale positie hebben dan niet-migranten. Er zijn aanwijzingen dat generieke programma's voor diverse kinderen en hun ouders kunnen werken (o.a. Wilson et al. 
2003; Bjørknes en Manger 2013), maar gedegen empirisch onderzoek hiernaar is, zeker ook in Nederland, nog beperkt.

Eén voorwaarde voor effectiviteit van dezelfde interventie voor verschillende doelgroepen is dat het theoretisch model waarop de interventie is gebaseerd, aansluit bij de risicofactoren en beschermende factoren van de verschillende doelgroepen (zie ook Stap 1 van de Meetladder Diversiteit; Pels et al. 2009). Bijvoorbeeld, als kinderen in sommige etnische groepen probleemgedrag ontwikkelen door dwingende ouder-kindinteracties, maar in andere etnische groepen door observationeel leren door het opgroeien in een gewelddadige wijk, dan hebben deze etnische groepen mogelijk een ander type interventie nodig.

Daarnaast is het belangrijk dat de interventie ofwel is toegespitst op de opvoedingsdoelen, normen en waarden van specifieke typen gezinnen, ofwel voldoende flexibel is om aan te sluiten bij de doelen, normen en waarden van verschillende typen gezinnen. Tot slot kunnen taalbarrières een probleem zijn voor effectieve hulpverlening bij gezinnen met een migratieachtergrond, indien ouders de Nederlandse taal slechts beperkt machtig zijn (Priebe et al. 2011).

\section{Opleidingsniveau}

Kinderen uit gezinnen waar ouders een lager opleidingsniveau hebben, hebben een grotere kans op de ontwikkeling van gedragsproblemen. Dit kan onder andere worden verklaard doordat lager opgeleide ouders meer stress ervaren, wat hun eigen mentale gezondheid en opvoedgedrag beïnvloedt (o.a. Conger et al. 1992). Deze stress zorgt er mogelijk ook voor dat ouders minder kunnen profiteren van geboden hulp. Ook zijn laagopgeleide ouders soms minder taalvaardig, wat een barrière kan zijn bij het tot zich nemen van cursusstof in de vorm van een boek of geschreven materialen.

Er is weinig consensus over of gezinnen met een lager opleidingsniveau inderdaad minder baat hebben bij ouderinterventies (zie bijvoorbeeld de tegenstrijdige bevindingen van Gardner et al. 2009; Leijten et al. 2012; en MacKenzie et al. 2004). Eén mogelijke verklaring hiervoor is dat de betekenis van een laag opleidingsniveau verschilt tussen landen. Waar een laag opleidingsniveau in sommige landen vaker gepaard gaat met armoede, is er in andere landen sprake van een beter sociaal en economisch vangnet voor deze gezinnen. In deze studie kijken we binnen Nederland of hoger en lager opgeleide gezinnen evenveel profiteren van een ouderinterventie om gedragsproblemen te verminderen.

\section{Ernst van de gedragsproblemen}

Bij kinderen met relatief veel gedragsproblemen is de kans op verbetering groter. Ook zijn hun ouders mogelijk meer gemotiveerd om hun opvoedgedrag te veranderen. Meta-analyses van de effecten van ouderinterventies laten dan ook zien dat met name kinderen die meer gedragsproblemen hebben, profiteren van 
ouderinterventies (o.a. Menting et al. 2013). Echter, gedragsproblemen die al op jonge leeftijd zichtbaar worden, zijn relatief stabiel in de loop van de tijd (Moffitt en Caspi 2001) en sommige studies vinden juist dat kinderen met relatief veel gedragsproblemen minder profiteren van interventies (Kazdin en Wassell 2000). In onze studie met grote aantallen van zowel kinderen met relatief veel als weinig gedragsproblemen toetsen we daarom of ouderinterventies met name effectief zijn voor kinderen met relatief veel gedragsproblemen.

\section{Bijkomstige ADHD-symptomen en/of emotionele problemen}

Gedragsproblemen staan vaak niet op zichzelf. Kinderen met gedragsproblemen hebben vaker dan andere kinderen ook ADHD-symptomen en/of emotionele problemen (Nadder et al. 2002). Ze hebben dus vaker dan andere kinderen moeite om zich te concentreren, reageren vaker impulsief en voelen zich vaker neerslachtig en angstig. Dit roept bij veel professionals de vraag op of dergelijke bijkomstige problemen de effectiviteit van ouderinterventies voor het verminderen van gedragsproblemen in de weg staan. Studies naar kinderen met zowel gedragsproblemen als ADHD-symptomen vinden hiervoor doorgaans geen bewijs (Bjørnebekk et al. 2015; Jarrett et al. 2014), maar de hoeveelheid onderzoek naar de effectiviteit van interventies bij meer of minder complexere problematiek is beperkt (Ollendick et al. 2008). In deze studie toetsen we of bijkomstige ADHD-symptomen of emotionele problemen de effectiviteit van ouderinterventies voor gedagsproblemen bij kinderen beïnvloeden.

\section{Doel van dit onderzoek}

Het doel van dit onderzoek is om zicht te krijgen op de mate waarin zeer verschillende gezinnen in Nederland - in termen van migratieachtergrond, opleidingsniveau, en ernst en bijkomstige problematiek - profiteren van de ouderinterventie Incredible Years.

\section{Methode}

\section{Procedure}

We hebben de gegevens van de individuele gezinnen uit elk van de vier studies naar Incredible Years in Nederland samengevoegd. Tab. 1 geeft een overzicht van deze vier studies. Drie studies waren een randomized controlled trial (Menting et al. 2014; Leijten et al. 2017b; Weeland et al. 2017); één studie maakte gebruik van een matched control group (Posthumus et al. 2012). Ouders van alle kinderen hebben schriftelijk toestemming gegeven voor gebruik van hun gegevens voor onderzoek naar de effectiviteit van Incredible Years. De procedures van elk van 
Tabel 1 Overzicht van de vier studies en hun gezinnen

\begin{tabular}{|c|c|c|c|c|}
\hline & $\begin{array}{l}\text { Studie \#1 } \\
\text { (Posthumus } \\
\text { et al. 2012) }\end{array}$ & $\begin{array}{l}\text { Studie \#2 } \\
\text { (Menting } \\
\text { et al. 2014) }\end{array}$ & $\begin{array}{l}\text { Studie \#3 } \\
\text { (Leijten } \\
\text { et al. 2018) }\end{array}$ & $\begin{array}{l}\text { Studie \#4 } \\
\text { (Weeland } \\
\text { et al. 2017) }\end{array}$ \\
\hline \multicolumn{5}{|l|}{ studiekenmerken } \\
\hline - design & $\begin{array}{l}\text { matched } \\
\text { control group }\end{array}$ & $\mathrm{RCT}$ & $\mathrm{RCT}$ & $\mathrm{RCT}$ \\
\hline - antal gezinnen & 144 & 99 & 156 & 387 \\
\hline - IY-versie & $\begin{array}{l}\text { BASIC }+ \\
\text { ADVANCED }\end{array}$ & $\begin{array}{l}\text { BASIC + } \\
\text { thuisbezoeken }\end{array}$ & BASIC & BASIC \\
\hline - aantal IY-sessies; $M$ & 18 & 16 & $14,46^{\mathrm{a}}$ & 14 \\
\hline - preventielevel & $\begin{array}{l}\text { indicatieve } \\
\text { preventie }\end{array}$ & $\begin{array}{l}\text { selectieve } \\
\text { preventie }\end{array}$ & $\begin{array}{l}\text { selectieve } \\
\text { preventie \& } \\
\text { behandeling }\end{array}$ & $\begin{array}{l}\text { indicatieve } \\
\text { preventie }\end{array}$ \\
\hline \multicolumn{5}{|l|}{ gezinskenmerken } \\
\hline - leeftijd kind; $M(S D)$ & $4,23(2,87)$ & $6,31(2,69)$ & $\begin{array}{l}5,60 \\
(1,34)\end{array}$ & $\begin{array}{c}6,31 \\
(1,33)\end{array}$ \\
\hline - geslacht kind (\% jongens) & $71 \%$ & $52 \%$ & $62 \%$ & $55 \%$ \\
\hline - opleidingsniveau ${ }^{\mathrm{b}} ; M(S D)$ & $3,57(0,95)$ & $1,78(0,94)$ & $\begin{array}{l}2,68 \\
(1,16)\end{array}$ & $\begin{array}{l}3,47 \\
(1,03)\end{array}$ \\
\hline $\begin{array}{l}\text { - \% migratieachtergrond } \\
\text { gedragsproblematiek }\end{array}$ & $5 \%$ & $78 \%$ & $65 \%$ & $11 \%$ \\
\hline $\begin{array}{l}\text { - ECBI-score voormeting; } M \\
\text { (SD) }\end{array}$ & $\begin{array}{l}129,88 \\
(26,98)\end{array}$ & $\begin{array}{l}110,09 \\
(31,13)\end{array}$ & $\begin{array}{l}124,17 \\
(33,03)\end{array}$ & $\begin{array}{l}133,27 \\
(19,24)\end{array}$ \\
\hline $\begin{array}{l}\text { - ECBI-score nameting; } M \\
(S D)\end{array}$ & $\begin{array}{l}122,30 \\
(27,99)\end{array}$ & $\begin{array}{r}98,95 \\
(23,42)\end{array}$ & $\begin{array}{l}114,57 \\
(31,35)\end{array}$ & $\begin{array}{l}125,69 \\
(19,32)\end{array}$ \\
\hline \multicolumn{5}{|l|}{ bijkomstige problematiek } \\
\hline $\begin{array}{l}\text { - SDQ ADHD-symptomen; } M \\
\quad(S D)\end{array}$ & $4,59(2,75)$ & $4,42(2,85)$ & $\begin{array}{r}5,71 \\
(2,72)\end{array}$ & $\begin{array}{r}5,79 \\
(2,67)\end{array}$ \\
\hline $\begin{array}{l}\text { - SDQ emotionele proble- } \\
\text { men; } M(S D)\end{array}$ & $2,15(2,08)$ & $2,52(2,13)$ & $\begin{array}{l}3,12 \\
(2,34)\end{array}$ & $\begin{array}{c}3,32 \\
(2,40)\end{array}$ \\
\hline
\end{tabular}

$M$ gemiddelde, $S D$ standaardafwijking, $I Y$ Incredible Years, $R C T$ randomized controlled trial, ECBI Eyberg Child Behavior Inventory, $S D Q$ Strengths and Difficulties Questionnaire

${ }^{\text {a}}$ Studie \#3 bestond uit verschillende versies van het IY BASIC-programma, omdat de richtlijnen over de duur van de interventie gedurende de studie werden aangepast

${ }^{\mathrm{b}}$ Opleidingsniveau: 1 = basisschool of minder, $2=$ middelbare school, $3=\mathrm{mbo}, 4=\mathrm{hbo}, 5=$ universiteit

de studies zijn goedgekeurd door de ethische commissie van de Faculteit Sociale Wetenschappen van de Universiteit Utrecht en die van het UMC Utrecht.

Wervingsprocedures varieerden per studie. In Studie \#1 en Studie \#4 ontvingen gezinnen met kinderen in de juiste leeftijdscategorie in een aantal gemeenten in de provincies Utrecht en Flevoland de Child Behavior Checklist (CBCL; Studie \#1) of de Eyberg Child Behavior Inventory (ECBI; Studie \#4). Ongeveer de helft van de gezinnen retourneerde de ingevulde vragenlijst. Gezinnen waarvan kinderen boven het $80^{\mathrm{e}}$ percentiel scoorden op de CBCL, of boven het $75^{\mathrm{e}}$ percentiel op de ECBI, werden uitgenodigd voor deelname aan de studie. In Studie \#2 werden moeders uit heel Nederland die recent waren vrijgekomen uit detentie ( $<6$ maanden) of die op korte termijn zouden vrijkomen ( $<3$ maanden) uitgenodigd voor deelname. In 
Studie \#3 werden zowel gezinnen verwezen voor gedragsproblemen naar Altrecht (GGZ Utrecht) uitgenodigd voor deelname, als gezinnen met kinderen op scholen in diverse multiculturele buurten in Utrecht, Nieuwegein en Apeldoorn.

\section{Deelnemende gezinnen}

In totaal namen 786 gezinnen deel (452 gezinnen ontvingen Incredible Years; 334 gezinnen kwamen in de controleconditie). Kinderen waren tussen de 2 en 10 jaar oud $(M=5,79 ; S D=1,66)$. Er was veel spreiding in het opleidingsniveau van de ouders. Elf procent van de ouders had alleen de basisschool afgerond, $20 \%$ de middelbare school, $28 \%$ een mbo-opleiding, $28 \%$ een hbo-opleiding en $13 \%$ een universitaire studie. Ongeveer een derde van de gezinnen had een migratieachtergrond. De meest voorkomende achtergronden waren Marokkaans (8\%), Surinaams of Antilliaans (7\%), Latijns-Amerikaans (4\%) en Turks (4\%).

Uit elk gezin vulde een van de ouders vragenlijsten in over het gedrag van kinderen. Dit was in de meeste gevallen de moeder. Omdat de interventie zowel werd ingezet voor preventie- als voor behandeldoeleinden varieerde de ernst van gedragsproblemen van de kinderen tussen zeer laag (twee standaardafwijkingen onder het populatiegemiddelde) tot zeer ernstig (boven het $98^{\mathrm{e}}$ percentiel). Ongeveer de helft van de kinderen liet ADHD-symptomen zien (22\% subklinisch; $25 \%$ klinisch) en ongeveer een derde van de kinderen had bijkomstige emotionele problemen (10\% subklinisch; $19 \%$ klinisch).

\section{Meetinstrumenten}

Migratieachtergrond Het al dan niet hebben van een migratieachtergrond, werd zo veel mogelijk vastgesteld op basis van het geboorteland van de ouders of grootouders (o.a. in Studie \#4), al waren deze gegevens niet altijd beschikbaar. Studie \#1 had geen gegevens over het geboorteland van de ouders, maar wel over het geboorteland van het kind. Voor deze studie codeerden we ouders als migrantenouders indien het kind niet in Nederland was geboren. In Studie \#2 is zowel gevraagd naar het geboorteland van de ouders, als het geboorteland van de grootouders. Indien een van de grootouders niet in Nederland was geboren, codeerden we dit als het hebben van een migratieachtergrond. In Studie \#3 namen meerdere ouders deel die zelf in Nederland waren geboren, maar van wie één of beide ouders in Marokko of Turkije was geboren. Deze ouders werden in dit onderzoek meegenomen als hebbende een migratieachtergrond.

Opleidingsniveau Ouders gaven aan wat hun hoogst afgeronde opleiding was. Alle studies gebruikten hiervoor dezelfde indeling: basisschool (gecodeerd als 1), middelbare school (2), mbo (3), hbo (4) of universiteit (5). In sommige studies was informatie over het opleidingsniveau van beide ouders beschikbaar. Voor 
consistentiedoeleinden is echter gebruikgemaakt van het opleidingsniveau van de zelfbenoemde primaire ouder (doorgaans de moeder).

Gedragsproblemen Gedragsproblemen zijn gemeten met de intensiteitsschaal van de ECBI (Eyberg en Ross 1978). Op deze vragenlijst geven ouders voor 36 gedragingen, zoals 'houdt zich niet aan huisregels' en 'gedraagt zich opstandig', aan hoe vaak hun kind deze vertoont $(1=$ nooit; $7=$ altijd $)$. Meerdere studies hebben laten zien dat de ECBI een betrouwbaar en valide instrument is om gedragsproblemen te meten (o.a. Abrahamse et al. 2015). De interne consistentie van deze vragenlijst in de samengevoegde data was Cronbachs $\alpha=0,90$.

ADHD-symptomen ADHD-symptomen zijn gemeten met de hyperactiviteit- en aandachtsproblemenschaal van de Strengths and Difficulties Questionnaire (SDQ; Goodman 1997; Widenfelt et al. 2003). Op deze vragenlijst geven ouders voor vijf gedragingen, zoals 'kan niet lang stilzitten' en 'gemakkelijk afgeleid', aan of deze van toepassing zijn op hun kind $(0=$ niet waar; $2=$ zeker waar $)$. Ouders in Studie \#1 vulden in plaats van de SDQ de aandachtsproblemenschaal van de CBCL (Achenbach en Rescorla 2000) in. Deze schalen van de SDQ en CBCL hangen vrij sterk samen (bijvoorbeeld $r=0,71$ in Goodman en Scott 1999). We hebben de CBCL-scores omgezet naar SDQ-scores met behulp van normdeviatiescores. Dit betekent dat we deze score als een kind een score had op de CBCL die gelijkstond aan bijvoorbeeld een halve standaardafwijking boven het populatiegemiddelde, omzetten naar een score op de SDQ die gelijkstond aan een halve standaardafwijking boven het populatiegemiddelde. De interne consistentie van de twee schalen om ADHD-symptomen te meten varieerde tussen Cronbachs $\alpha=0,78$ en $\alpha=0,80$.

Emotionele problemen Emotionele problemen zijn gemeten met de emotioneleproblemenschaal van de SDQ (Goodman 1997; Widenfelt et al. 2003). Op deze vragenlijst geven ouders voor vijf gedragingen, zoals 'vaak ongelukkig' en 'is snel angstig', aan of deze van toepassing zijn op hun kind $(0=$ niet waar; $2=$ zeker waar). Ouders in Studie \#1 vulden de internaliserende-problematiekschaal van de CBCL (Achenbach en Rescorla 2000) in. Ook deze SDQ- en CBCL-schalen hangen vrij sterk samen (bijvoorbeeld $r=0,74$ in Goodman en Scott 1999), en ook hier hebben we daarom met behulp van normdeviatiescores de CBCL-scores omgezet naar SDQ-scores. De interne consistentie van de deze schalen varieerde tussen Cronbachs $\alpha=0,64$ en $\alpha=0,67$.

\section{Incredible Years}

Het ouderprogramma Incredible Years (Webster-Stratton 2001) is ontwikkeld in de Verenigde Staten en in tientallen studies onderzocht op effectiviteit (Menting et al. 2013). In Nederland is de interventie opgenomen als 'effectief volgens sterke aanwijzingen' in de Databank Effectieve Jeugdinterventies van het Nederlands Jeugd- 
instituut. Behalve vertaling van het programmamateriaal naar het Nederlands zijn geen culturele aanpassingen aan de originele interventie gedaan. Incredible Years bestaat uit twaalf tot achttien wekelijkse groepsbijeenkomsten. Kernvaardigheden die ouders leren zijn: kindgericht spelen, het geven van complimenten en beloningen om gewenst gedrag bij kinderen te versterken, het stellen van grenzen, en het gebruik van negatieve consequenties (bijvoorbeeld negeren en time-out) om ongewenst gedrag bij kinderen te verminderen. Verder leren ouders hoe ze de sociale, emotionele en academische vaardigheden van kinderen kunnen coachen.

Incredible Years wordt uitgevoerd door twee groepsleiders. In elk van de studies hadden beide groepsleiders de Incredible Years-workshop gevolgd en was minimaal één groepsleider gecertificeerd als Incredible Years-group leader. Incredible Years-groepsleiders hanteren een zogenaamde collaboratieve benadering: ze faciliteren groepsdiscussies en moedigen ouders aan om zelf oplossingen voor problemen te vinden, in plaats van dat ze als expert voor de groep staan. Ze kiezen dus een coachende in plaats van een leidende opstelling. Er wordt naast groepsdiscussies veel gebruikgemaakt van brainstormen, het bekijken en bespreken van videofragmenten, en rollenspelen. Tussen de bijeenkomsten door oefenen ouders thuis met nieuwe vaardigheden en hebben ze telefonisch contact met een andere ouder uit de groep.

Alle bijeenkomsten werden gegeven in het Nederlands. Met ouders die beperkt Nederlands spraken werd overlegd over de aanwezigheid van een tolk. Alle ouders gaven de voorkeur aan informeel tolken door andere ouders of door een bekende (bijv. een zus of vriendin) in plaats van door een professionele tolk. Ouders ontvingen het boek Pittige jaren (Webster-Stratton 2007). Indien ouders de Nederlandse taal minder machtig waren, ontvingen ze naast het boek een vereenvoudigde samenvatting en hand-outs van het boek (Studie \#2 en \#3). In groepen met ouders die de Nederlandse taal onvoldoende beheersten om het boek te lezen, werd de inhoud van het boek nadrukkelijker besproken in de bijeenkomsten.

De programma-integriteit werd bewaakt door het maken van video-opnamen van sessies, die werden besproken in frequente intervisie- en supervisiebijeenkomsten. Verder vulden de groepsleiders voor elk van de bijeenkomsten checklists in over de programmaonderdelen die aan bod waren gekomen, om zicht te krijgen op de mate waarin alle essentiële onderdelen van de interventie waren behandeld.

Bij de verschillende studies samengenomen nam $16 \%$ van de ouders in de Incredible Years-conditie toch niet deel aan de interventie. Ouders die wel deelnamen woonden per studie gemiddeld $68 \%$ tot $79 \%$ van de bijeenkomsten bij. Uitval was niet selectief. Met andere woorden, ouders met een migratieachtergrond of een laag opleidingsniveau vielen niet vaker uit dan ouders zonder migratieachtergrond of met een hoger opleidingsniveau. Alle gezinnen in de Incredible Years-conditie zijn, ongeacht hun daadwerkelijke deelname aan Incredible Years, meegenomen in de analyses in deze studie (intention to treat analyses). 


\section{Analyses}

Om de onderzoeksvragen te beantwoorden, hebben we multilevel-regressieanalyses uitgevoerd. Hierbij hebben we rekening gehouden met de geneste structuur van de data: vragenlijsten over het gedrag van de kinderen werden ingevuld door individuele gezinnen, maar deze gezinnen volgden Incredible Years in groepsverband, en de verschillende Incredible Years-groepen maakten weer deel uit van een van de vier studies. In de multilevel-analyses in HLM 6,08 (Raudenbush et al. 2004) hebben we hiermee rekening gehouden door te corrigeren voor het feit dat de effectiviteit van Incredible Years misschien per studie of per Incredible Yearsgroep verschilt.

Uitkomstmaat in alle analyses was de mate van gedragsproblemen bij de kinderen na afloop van Incredible Years, gecorrigeerd voor de gedragsproblemen voorafgaand aan Incredible Years. In aparte analyses hebben we vervolgens gekeken of de vijf gezinskenmerken (migratieachtergrond, opleidingsniveau, ernst gedragsproblemen, ADHD-symptomen en emotionele problemen) van invloed waren op het effect van Incredible Years op de gedragsproblemen bij de kinderen ('moderatoranalyses').

\section{Resultaten}

\section{Algemene effectiviteit van Incredible Years}

Incredible Years had een klein tot middelgroot effect op de gedragsproblemen van kinderen (Cohens $d=-0,34 ; 95 \%$-betrouwbaarheidsinterval $-0,49$ tot $-0,19$; tab. 1). Wanneer ouders deelnamen aan Incredible Years verminderden gedragsproblemen van kinderen sterker (gemiddeld van 127,56 naar 116,61 op de ECBI) dan wanneer ouders in de controleconditie zaten (gemiddeld van 129,33 naar 125,14). Voorafgaand aan Incredible Years scoorde $24 \%$ van de kinderen in de Incredible Years-conditie in het klinische gebied voor gedragsproblemen $\left(>90^{\mathrm{e}}\right.$ percentiel). $\mathrm{Na}$ Incredible Years was dit $10 \%$. Voor kinderen in de controleconditie was dit $23 \%$ aan het begin van de studie en $17 \%$ aan het einde van de studie. Incredible Years leidde dus tot een significante en klinisch relevante afname van gedragsproblemen bij kinderen. De spreiding in effectiviteit tussen gezinnen binnen de interventiegroep was echter groot: scores op een maat voor betrouwbare verbetering (reliable change index) varieerden van $-7,94$ tot 6,23 .

\section{Wie profiteert het meest van Incredible Years?}

Het effect van Incredible Years op de gedragsproblemen van kinderen werd niet beïnvloed door het hebben van een migratieachtergrond $(\beta=-6,68 ; t(46)=-1,15$; $p=0,257)$. Kinderen van ouders met een migratieachtergrond profiteerden dus niet minder (of meer) van deze opvoedingsondersteuning dan kinderen van ouders 
zonder migratieachtergrond. We vonden hetzelfde voor kinderen van ouders met verschillende opleidingsniveaus: het effect van Incredible Years op de gedragsproblemen van kinderen werd niet beïnvloed door het opleidingsniveau van ouders $(\beta=-1,35 ; t(46)=0,66 ; p=0,515)$. Kinderen van laagopgeleide ouders profiteerden dus eveneens niet minder (of meer) van opvoedingsondersteuning dan kinderen van hoger opgeleide ouders.

De effectiviteit van Incredible Years werd wel beïnvloed door de ernst van de gedragsproblemen van kinderen: Incredible Years zorgde voor een sterkere vermindering van gedragsproblemen bij kinderen met ernstiger gedragsproblemen dan bij kinderen met minder ernstige gedragsproblemen $(\beta=-0,19 ; t(46)=-2,31$; $p=0,025)$. Hoe ernstiger de gedragsproblemen van kinderen voor aanvang waren, des te meer vooruitgang lieten de kinderen zien. Ter illustratie: kinderen die voorafgaand aan de interventie een standaarddeviatie boven het steekproefgemiddelde scoorden op de ECBI lieten gemiddeld een afname van 27 punten op de ECBI zien, wat ongeveer gelijkstaat aan een standaarddeviatie. Kinderen die voorafgaand aan de interventie een standaarddeviatie onder het steekproefgemiddelde scoorden op de ECBI, lieten gemiddeld geen afname op de ECBI zien.

De effectiviteit van Incredible Years werd niet beïnvloed door de mate waarin kinderen ADHD-symptomen hadden $(\beta=-6,68 ; t(46)=-1,15 ; p=0,257)$. Kinderen met meer hyperactiviteits- en aandachtsproblemen profiteerden dus niet minder (of meer) van de interventie, in termen van verminderde gedragsproblemen, dan kinderen met minder hyperactiviteits- en aandachtsproblemen.

Tot slot werd de effectiviteit van Incredible Years wel beïnvloed door de mate waarin kinderen bijkomstige emotionele problemen hadden $(\beta=-2,27$; $t(46)=-2,56 ; p=0,014)$. De interventie zorgde bij kinderen met meer emotionele problemen voor een sterkere afname van gedragsproblemen.

\section{Discussie}

In deze studie hebben we gekeken welke gezinnen meer of minder baat hebben bij een gedragstherapeutische ouderinterventie om gedragsproblemen bij kinderen te verminderen. We hebben voor vijf gezinskenmerken getoetst of ze invloed hebben op de effectiviteit van Incredible Years in Nederland. Incredible Years bleek effectief in het verminderen van gedragsproblemen bij kinderen. Het hebben van een migratieachtergrond of een laag opleidingsniveau had geen invloed op deze effectiviteit: de effecten van Incredible Years waren niet anders voor gezinnen met of zonder migratieachtergrond en varieerden niet met het opleidingsniveau van ouders. Hoewel Incredible Years niet specifiek is ontwikkeld voor gezinnen met een migratieachtergrond, was de interventie voor deze gezinnen dus niet minder effectief dan voor gezinnen zonder migratieachtergrond. Dit suggereert dat het theoretische model van de interventie, alsmede de opvoeddoelen, normen en waarden die besproken worden in de interventie, voldoende aansluiten bij risicofactoren en beschermende factoren en opvoeddoelen, normen en waarden van gezinnen met diverse culturele achtergronden. 
Hetzelfde geldt voor laagopgeleide gezinnen: Incredible Years was voor deze gezinnen niet minder effectief dan voor gezinnen met een hoger opleidingsniveau. Met name oudere studies, en meta-analyses grotendeels gebaseerd op oudere studies, suggereren soms dat laagopgeleide gezinnen minder profiteren van ouderinterventies, met name wanneer dit groepsinterventies zijn (Lundahl et al. 2006). Recentere studies vonden hiervoor weinig bewijs en sommige studies vonden zelfs dat lager opgeleide gezinnen meer profiteren (o.a. Gardner et al. 2009). Onze bevindingen laten zien dat de groepsinterventie Incredible Years even effectief is voor lager opgeleide als voor hoger opgeleide gezinnen.

We hebben voor deze studie gebruikgemaakt van data van bijna achthonderd gezinnen uit vier verschillende studies. Dit sterkt ons vertrouwen in de bevindingen dat de migratieachtergrond en het opleidingsniveau van ouders geen rol spelen bij de effectiviteit van Incredible Years. Met dit grote aantal gezinnen hadden we namelijk zelfs kleine effecten van deze gezinskenmerken op de effectiviteit kunnen ontdekken. Hoe kan het dat zulke diverse gezinnen evenveel baat hebben bij dezelfde interventie, wanneer er bijvoorbeeld sprake is van cultuurverschillen tussen ouders, de interventie en de therapeuten, en van mogelijke taalbarrières? Een plausibel antwoord op deze vraag is dat Incredible Years weliswaar geen aanpassingen doet - alle ouders krijgen hetzelfde programma, ongeacht hun etnische achtergrond of opleidingsniveau (Webster-Stratton 2009), maar voldoende flexibel is om aansluiting te vinden bij gezinnen met verschillende achtergronden. Dit komt tot uitdrukking in de collaboratieve benadering, waarbij groepsleiders ouders niet vertellen wat goede oplossingen zijn voor moeilijk gedrag van kinderen, maar waarbij zij gedachtewisselingen tussen ouders hierover begeleiden. Ouders worden op deze manier aangemoedigd om oplossingen te vinden die aansluiten bij hun eigen waarden en om opvoedtechnieken zoals het geven van complimenten en belonen van positief gedrag te gebruiken op een manier die bij hen past (WebsterStratton 2009). Dit is mogelijk niet alleen belangrijk voor ouders met verschillende culturele achtergronden in termen van land van herkomst, maar ook voor gezinnen binnen dezelfde cultuur die verschillen in opvattingen, normen en waarden. Verder draagt deze houding de boodschap uit dat ouders zelf de expert zijn in de omgang met hun kind en goede ideeën en vaardigheden hebben om het gedrag van kinderen te veranderen ('empowerment'). Verder wordt in de interventie weliswaar gebruikgemaakt van een boek en andere geschreven materialen, maar veel onderdelen van Incredible Years vragen weinig taalvaardigheid van ouders: ouders leren nieuwe opvoedtechnieken vooral door het kijken naar videobeelden en door het doen van rollenspelen.

De ernst van de gedragsproblemen van kinderen speelde wel een rol bij de effectiviteit: kinderen met ernstiger gedragsproblemen en kinderen met meer emotionele problemen lieten bij deelname van ouders aan Incredible Years een grotere afname van probleemgedrag zien. Dit gold niet voor het hebben van meer ADHD-symptomen - ADHD-symptomen hadden geen invloed op de effectiviteit van Incredible Years.

Gedragstherapeutische ouderinterventies worden niet alleen vaak geadviseerd bij gedragsproblemen bij kinderen, maar ook bij ADHD-symptomen, vooral wan- 
neer de nadelige gevolgen van deze symptomen nog niet heel ernstig zijn. Onze resultaten laten zien dat de aanwezigheid van ADHD-symptomen het verminderen van gedragsproblemen niet in de weg staat. Daarnaast zijn er aanwijzingen dat Incredible Years naast gedragsproblemen ook door de ouder gerapporteerde ADHDsymptomen vermindert (Leijten et al. 2018).

Het hebben van bijkomstige emotionele problemen bij kinderen leidde niet tot verminderde effectiviteit van de ouderinterventie. Sterker nog, zowel de resultaten van onze studie, als die van andere studies (o.a. Jarrett et al. 2014), lieten zien dat juist kinderen die naast gedragsproblemen ook emotionele problemen hebben extra profiteren van ouderinterventies. Deze kinderen lieten de grootste afname van gedragsproblemen zien. Er zijn aanwijzingen dat er weliswaar verschillende opvoedprocessen een rol spelen bij de ontwikkeling van gedragsproblemen en emotionele problemen, hardheid en vijandigheid van ouders een rol spelen in de ontwikkeling van beide soorten problemen en juist ook bij het samengaan van beide problemen (Kim et al. 2003). Met name kinderen die zowel gedragsproblemen als emotionele problemen hebben, groeien dus vaak op in gezinnen die worden gekenmerkt door hardheid en vijandigheid, wat mogelijk verklaart waarom juist deze kinderen profiteren van opvoedingsondersteuning die dit opvoedgedrag verandert.

De bevinding dat de migratieachtergrond, een laag opleidingsniveau en het samengaan van verschillende soorten problematiek de effectiviteit van Incredible Years niet nadelig beïnvloeden is hoopgevend. Echter, het biedt geen oplossing voor het probleem dat er grote verschillen zijn tussen gezinnen in de mate waarin ze profiteren van ouderinterventies. Deze verschillen worden blijkbaar niet veroorzaakt door migratieachtergrond, opleiding of ADHD-symptomen. Waarom is het zo moeilijk om zicht te krijgen op wat deze verschillen veroorzaakt en welke gezinnen meer of minder profiteren? Veel onderzoek richt zich op algemene en demografische kenmerken van ouders en kinderen, zoals opleidingsniveau en geslacht. Mogelijk zijn het niet deze grove en 'statische' gezinskenmerken die het verschil maken tussen effectiviteit en ineffectiviteit. De meeste ouderinterventies maken gebruik van therapeuten. Het contact tussen gezinnen en therapeuten wordt vormgegeven door beiden en ontwikkelt zich in de loop van de tijd. Preciezere analyse van deze dynamische interacties tussen ouders en therapeuten is mogelijk nodig om zicht te krijgen op wanneer ouderinterventies succesvol zijn.

Veel onderzoek naar het identificeren van gezinnen die meer of minder baat hebben bij ouderinterventies probeert enkele individuele kenmerken van gezinnen te vinden die verschillen in effectiviteit verklaren. In werkelijkheid is het mogelijk echter niet één kenmerk van een gezin (bijvoorbeeld culturele achtergrond of type probleemgedrag van het kind) dat een rol speelt, maar een complexe samenhang van deze kenmerken. Meer persoonsgericht onderzoek kan typen gezinnen van elkaar onderscheiden op basis van hoeveel zij profiteren van ouderinterventies. Door vervolgens te kijken naar wat deze typen gezinnen kenmerkt en wat ze van elkaar onderscheidt, krijgen we wellicht meer zicht op de gezinskenmerken die verschillen in effectiviteit verklaren (zie o.a. Pelham et al. 2017 voor een voorbeeld). 
Dit onderzoek heeft een aantal beperkingen. Allereerst is onze maat van gedragsproblemen bij kinderen gebaseerd op de rapportage van ouders. Ouders wisten of ze wel of niet hadden deelgenomen aan de interventie, wat hun rapportage mogelijk beïnvloedt (Sonuga-Barke et al. 2013). Zo willen ouders die hebben deelgenomen aan de interventie misschien graag positieve verandering zien. We waren bij onze keuze voor instrumenten afhankelijk van de beschikbaarheid van gegevens in de oorspronkelijke studies. Leerkrachtrapportage en gedragsobservaties waren slechts voor een deel van de studies en gezinnen beschikbaar. Een meta-analyse van alle studies naar Incredible Years laat wel zien dat effecten volgens verschillende informanten en gedragsobservaties vergelijkbaar positief zijn (Menting et al. 2013).

Verder hebben we alleen gekeken naar de effectiviteit op korte termijn. We kunnen daarom geen uitspraken doen over verschillen in effectiviteit bij de verschillende typen gezinnen op langere termijn. Effecten van interventies zoals Incredible Years zijn echter doorgaans relatief stabiel (Posthumus et al. 2012; Aar et al. 2017).

Tot slot gebruikten drie studies de SDQ om ADHD-symptomen en emotionele problemen bij kinderen te meten en één studie de CBCL. Hoewel scores op deze instrumenten doorgaans sterk samenhangen (Goodman en Scott 1999), is onze benadering gebaseerd op de aanname dat beide instrumenten inderdaad dezelfde onderliggende problematiek meten.

Deze studie is een van de eerste die data van verschillende onderzoeken samenvoegt om zo preciezere uitspraken te doen over de effectiviteit van een ouderinterventie voor verschillende gezinnen. Ze laat zien dat het hebben van een migratieachtergrond, een laag opleidingsniveau of bijkomstige ADHD-symptomen er niet toe leidt dat gezinnen minder profiteren van het ouderprogramma Incredible Years om gedragsproblemen bij kinderen te verminderen. Verder wijst de studie uit dat kinderen met ernstiger gedragsproblemen en kinderen met bijkomstige emotionele problemen het meest profiteren. Op basis van deze studie concluderen we daarom dat het ouderprogramma Incredible Years even effectief is voor, en dus aangeboden kan worden aan, cultureel diverse gezinnen met kinderen met gedragsproblemen.

Dankbetuiging We bedanken alle onderzoekers, Incredible Years-groepsleiders en gezinnen die hebben bijgedragen aan de totstandkoming van de vier studies dit artikel.

Financiering Dit onderzoek is gefinancierd door ZonMw (project \#729101004). De vier oorspronkelijke studies werden mogelijk gemaakt door financiële ondersteuning van ZonMw (Studie \#1 en \#3), door financiële en organisatorische ondersteuning van het ministerie van Veiligheid en Justitie (Studie \#2) en door financiële ondersteuning van NWO (Studie \#4).

Belangenverstrengeling Maartje Raaijmakers is hoofdopleider Incredible Years in Nederland en betrokken bij de verspreiding en implementatie van Incredible Years in Nederland. De andere auteurs rapporteren geen mogelijke tegenstrijdige belangen. 


\section{Literatuur}

Aar, J. van, Leijten, P., Orobio de Castro, B., \& Overbeek, G. (2017). Sustained, fade-out or sleeper effects? A systematic review and meta-analysis of parenting interventions for disruptive child behavior. Clinical Psychology Review, 51, 153-163.

Abrahamse, M.E., Junger, M., Leijten, P., Boer, F., \& Lindauer, R. J.L. (2015). Identifying behavioural problems in a community sample and a multi-ethnic clinical sample of young children: psychometric properties of the Dutch Eyberg Child Behavior Inventory (ECBI). Journal of Psychopathology and Behavioral Assessment, 37, 679-691.

Achenbach, T. M., \& Rescorla, L. A. (2000). Manual for the ASEBA preschool forms and profiles. Burlington: University of Vermont, Research Center for Children, Youth, and Families.

Bjørknes, R., \& Manger, T. (2013). Can parent training alter parent practice and reduce conduct problems in ethnic minority children? A randomized controlled trial. Prevention Science, 14, 52-63.

Bjørnebekk, G., Kjøbli, J., \& Ogden, T. (2015). Children with conduct problems and co-occurring ADHD: behavioral improvements following parent management training. Child \& Family Behavior Therapy, 37, 1-19.

Brown, C.H., Sloboda, Z., Faggiano, F., Teasdale, B., Keller, F., Burkhart, G., \& Perrino, T. (2013). Methods for synthesizing findings on moderation effects across multiple randomized trials. Prevention Science, 14, 144-156.

Conger, R.D., Conger, K. J., Elder, G.H., Lorenz, F.O., Simons, R.L., \& Whitbeck, L.B. (1992). A family process model of economic hardship and adjustment of early adolescent boys. Child Development, 63, 526-541.

Eyberg, S.M., \& Ross, A.W. (1978). Assessment of child behavior problems: the validation of a new inventory. Journal of Clinical Child Psychology, 7, 113-116.

Gardner, F., Connell, A., Trentacosta, C. J., Shaw, D. S., Dishion, T.J., \& Wilson, M. N. (2009). Moderators of outcome in a brief family-centered intervention for preventing early problem behavior. Journal of Consulting and Clinical Psychology, 77, 543-553.

Goodman, R. (1997). The strengths and difficulties questionnaire: a research note. Journal of Child Psychology and Psychiatry, 38, 581-586.

Goodman, R., \& Scott, S. (1999). Comparing the strengths and difficulties questionnaire and the child behavior checklist: is small beautiful? Journal of Abnormal Child Psychology, 27, 17-24.

Jarrett, M., Siddiqui, S., Lochman, J., \& Qu, L. (2014). Internalizing problems as a predictor of change in externalizing problems in at-risk youth. Journal of Clinical Child \& Adolescent Psychology, 43, $27-35$.

Kazdin, A.E., \& Wassell, G. (2000). Therapeutic changes in children, parents, and families resulting from treatment of children with conduct problems. Journal of the American Academy of Child and Adolescent Psychiatry, 39, 414-420.

Kim, I. J., Ge, X., Brody, G.H., Conger, R. D., Gibbons, F. X., \& Simons, R. L. (2003). Parenting behaviors and the occurrence and co-occurrence of depressive symptoms and conduct problems among African American children. Journal of Family Psychology, 17, 571-583.

Leijten, P., Overbeek, G., \& Janssens, J.M. A. M. (2012). Effectiveness of a parent training program in (pre)adolescence: evidence from a randomized controlled trial. Journal of Adolescence, 35, 833-842.

Leijten, P., Melendez-Torres, G.J., Knerr, W., \& Gardner, F. (2016). Transported versus homegrown parenting interventions for reducing disruptive child behavior: a multilevel meta-regression study. Journal of the American Academy of Child and Adolescent Psychiatry, 55, 233-243.

Leijten, P., Raaijmakers, M. A. J., Orobio de Castro, B., Ban, E. van den, \& Matthys, W. (2017). Effectiveness of the Incredible Years parenting program for families with socioeconomically disadvantaged and ethnic minority backgrounds. Journal of Clinical Child \& Adolescent Psychology, 46, 59-73.

Leijten, P., Gardner, F., Landau, S., Harris, V., Mann, J., Hutchings, J., \& Scott, S. (2018). Harnessing the power of individual participant data in a meta-analysis of the benefits and harms of the Incredible Years parenting program. Journal of Child Psychology and Psychiatry, 59, 99-109.

Lundahl, B., Risser, H. J., \& Lovejoy, M.C. (2006). A meta-analysis of parent training: moderators and follow-up effects. Clinical Psychology Review, 26, 86-104.

MacKenzie, E.P., Fite, P.J., \& Bates, J.E. (2004). Predicting outcome in behavioral parent training: expected and unexpected results. Child \& Family Behavior Therapy, 26, 37-53. 
Menting, A. T.A., Orobio de Castro, B., \& Matthys, W. (2013). Effectiveness of the Incredible Years parent training to modify disruptive and prosocial child behavior: a meta-analytic review. Clinical Psychology Review, 33, 901-913.

Menting, A. T. A., Orobio de Castro, B., Wijngaards-de Meij, L., \& Matthys, W. (2014). A trial of parent training for mothers being released from incarceration and their children. Journal of Clinical Child \& Adolescent Psychology, 43, 381-396.

Miranda, J., Bernal, G., Lau, A., Kohn, L., Hwang, W.C., \& LaFromboise, T. (2005). State of the science on psychosocial interventions for ethnic minorities. Annual Review of Clinical Psychology, $1,113-142$.

Moffitt, T.E., \& Caspi, A. (2001). Childhood predictors differentiate life-course persistent and adolescence-limited antisocial pathways among males and females. Development and Psychopathology, $13,355-375$.

Nadder, T.S., Rutter, M., Silberg, J.L., Maes, H.H., \& Eaves, L. J. (2002). Genetic effects on the variation and covariation of attention deficit-hyperactivity disorder (ADHD) and oppositional-defiant disorder/conduct disorder (ODD/CD) symptomatologies across informant and occasion of measurement. Psychological Medicine, 32, 39-53.

Ng, M. Y., \& Weisz, J. R. (2016). Annual research review: building a science of personalized intervention for youth mental health. Journal of Child Psychology and Psychiatry, 57, 216-236.

Ollendick, T.H., Jarrett, M. A., Grills-Taquechel, A.E., Hovey, L.D., \& Wolff, J. C. (2008). Comorbidity as a predictor and moderator of treatment outcome in youth with anxiety, affective, attention deficit/hyperactivity disorder, and oppositional/conduct disorders. Clinical Psychology Review, 28, 1447-1471.

Pelham, W.E., Dishion, T. J., Tein, J. Y., Shaw, D. S., \& Wilson, M.N. (2017). What doesn't work for whom? Exploring heterogeneity in responsiveness to the family check-up in early childhood using a mixture model approach. Prevention Science. https://doi.org/10.1007/s11121-017-0805-1.

Pels, T., Distelbrink, M., \& Tan, S. (2009). Meetladder Diversiteit Interventies. Naar verhoging van bereik en effectiviteit van interventies voor verschillende (etnische) doelgroepen. Utrecht: VerweyJonker Instituut.

Posthumus, J.A., Raaijmakers, M.A.J., Maassen, G.H., Engeland, H. van, \& Matthys, W. (2012). Sustained effects of Incredible Years as a preventive intervention in preschool children with conduct problems. Journal of Abnormal Child Psychology, 40, 487-500.

Priebe, S., Sandhu, S., Dias, S., Gaddini, A., Greacen, T., Ioannidis, E., \& Riera, R. P. (2011). Good practice in health care for migrants: views and experiences of care professionals in 16 European countries. BMC Public Health, 11, 187-198.

Raudenbush, S.W., Bryk, A.S., \& Congdon, R. (2004). HLM 6 for Windows [Computer software]. Skokie: Scientific Software International.

Rutter, M., \& Pickles, A. (2016). Annual research review: threats to the validity of child psychiatry and psychology. Journal of Child Psychology and Psychiatry, 57, 398-416.

Scott, S., Spender, Q., Doolan, M., Jacobs, B., \& Aspland, H. (2001). Multicentre controlled trial of parenting groups for childhood antisocial behaviour in clinical practice. British Medical Journal, 323, 194-198.

Shelleby, E.C., \& Shaw, D. S. (2014). Outcomes of parenting interventions for child conduct problems: a review of differential effectiveness. Child Psychiatry \& Human Development, 45, 628-645.

Sonuga-Barke, E. J., Brandeis, D., Cortese, S., Daley, D., Ferrin, M., Holtmann, M., Dittmann, R. W., et al. (2013). Nonpharmacological interventions for ADHD: systematic review and meta-analyses of randomized controlled trials of dietary and psychological treatments. American Journal of Psychiatry, 170, 275-289.

Webster-Stratton, C. (2001). The incredible years: parents and children videotape series: a parenting course (BASIC). Seattle: Incredible Years.

Webster-Stratton, C. (2007). Pittige Jaren. Praktische gids bij het opvoeden van jonge kinderen. Houten: Bohn Stafleu van Loghum.

Webster-Stratton, C. (2009). Affirming diversity: multi-cultural collaboration to deliver the incredible years parent programs. International Journal of Child Health and Human Development, 2, 17-32.

Weeland, J., Chhangur, R.R., Giessen, D. van der, Matthys, W., Orobio de Castro, B., \& Overbeek, G. (2017). Intervention effectiveness of the Incredible Years parent training: new insights into sociodemographic and intervention-based moderators. Behavior Therapy, 48, 1-18. 
Weisz, J.R., \& Kazdin, A.E. (Eds.). (2010). Evidence-based psychotherapies for children and adolescents. New York, NY: Guilford Press.

Widenfelt, B. M. van, Goedhart, A.W., Treffers, P.D., \& Goodman, R. (2003). Dutch version of the Strengths and Difficulties Questionnaire (SDQ). European Child \& Adolescent Psychiatry, 12, 281-289.

Wilson, S. J., Lipsey, M.W., \& Soydan, H. (2003). Are mainstream programs for juvenile delinquency less effective with minority youth than majority youth? A meta-analysis of outcomes research. Research on Social Work Practice, 13, 3-26.

Dr. Patty Leijten is universitair docent bij de afdeling Preventieve Jeugdhulp en Opvoeding van de Universiteit van Amsterdam.

Dr. Ankie Menting is universitair docent bij de afdeling Ontwikkelingspsychologie van de Universiteit Utrecht.

Dr. Leoniek Wijngaards-de Meij is universitair hoofddocent bij de afdeling Methoden en Statistiek van de Universiteit Utrecht.

Dr. Maartje Raaijmakers is GZ-psycholoog in opleiding tot klinisch psycholoog bij Pro Persona en hoofdopleider Incredible Years in Nederland.

Prof. dr. Walter Matthys is emeritus hoogleraar bij de afdeling Kinder- en Jeugdstudies van de Universiteit Utrecht.

Prof. dr. Bram Orobio de Castro is hoogleraar bij de afdeling Ontwikkelingspsychologie van de Universiteit Utrecht. 